\title{
An Analysis of Intracellular Proteolytic Activities of Tetrahymena pyriformis GL
}

\author{
By MICHAEL J. NORTH* AND MARION WALKER \\ Department of Biological Science, University of Stirling, Stirling FK9 4LA, UK
}

(Received 30 December 1983; revised 29 February 1984)

\begin{abstract}
Five different assay conditions were used to analyse the intracellular proteolytic system of Tetrahymena pyriformis GL. Acid proteinase activity was measured using hide powder azure at $\mathrm{pH} 4$ and neutral proteinase activity was measured using hide powder azure and azocasein at $\mathrm{pH}$ 8 and two peptide nitroanilides at $\mathrm{pH} 7$. Differences between the activities were apparent from their sensitivity to proteinase inhibitors although all were likely to be due to cysteine proteinases. Indeed all were enhanced by the presence of $1 \mathrm{mM}$-DTT. The neutral activities could be resolved into at least three forms by ion-exchange chromatography, each form having a different specificity for the substrates used. The acid proteinase activity was similarly separated into different fractions. The intracellular activity of acid proteinase responded differently from that of the neutral activities to culture age or resuspension of cells in fresh medium and starvation buffer. Furthermore, analysis on sucrose density gradients showed that although the neutral activities had a similar subcellular distribution to one another this differed from that of the acid proteinase activity. This suggests that the physiological roles of the acid and neutral proteinases may differ. PAGE using gels containing haemoglobin to detect proteinases was less successful than with other species of protozoa. However, it did reveal multiple forms of acid proteinase.
\end{abstract}

\section{INTRODUCTION}

The proteolytic system of the ciliate Tetrahymena pyriformis is probably that most studied amongst protozoan species (Dickie \& Liener, 1962; Levy et al., 1976; Banno et al., 1982, 1983). Both acid proteinase and neutral proteinase activities have been described but it is not at all clear how many different types of enzyme are responsible for these. A number of assay procedures have been used, involving different substrates and pHs, and it is likely that these different methods measure different combinations of the proteinases present in T. pyriformis. Dickie \& Liener (1962) purified three forms of proteinase, one intracellular and two extracellular; their requirement for cysteine and EDTA indicated that they were cysteine proteinases. Banno et al. (1982) described four different forms of both intracellular and extracellular proteinases active towards AZC and Bz-Arg-Nan at neutral $\mathrm{pH}$ which could be separated by ion-exchange chromatography. These also had the properties of cysteine proteinases. Other workers too have described the separation of multiple forms of proteinase by ion-exchange chromatography (Levy et al., 1976; Blum, 1976). Levy et al. (1976) presented other evidence that $T$. pyriformis possesses more than one type of proteinase. Nevertheless, the relationship between the different proteinase activities has not been established clearly and the physiological significance of the multiple forms not fully explored.

We have undertaken an analysis of the proteolytic system of $T$. pyriformis using methods which have proved useful in distinguishing different types of proteinase in other species of

\footnotetext{
Abbreviations: Bz, benzoyl; Tos, tosyl; Nan, nitroanilide; AZC, azocasein; HPA, hide powder azure; PMSF, phenylmethylsulphonyl fluoride; TLCK, $N$ - $\alpha$-p-tosyl-L-lysine chloromethyl ketone; TPCK, L-1-tosylamide-2phenylethyl chloromethyl ketone; Pf, fluffy layer; $\mathrm{Pt}$, tightly packed layer.
} 
protozoa (North et al., 1983). The aim was to compare some properties of the activities detected using different assay conditions and to determine whether they could be distinguished from one another on the basis of differences in the response to changes in the physiological condition of the cells and with respect to subcellular localization. The results presented show that the proteinase activity detected at acid $\mathrm{pH}$ was different from those detected at neutral $\mathrm{pH}$. There were also variations between the neutral proteinase activities. Some of the assays used were found to be better than ones used previously and will be valuable in future work on $T$. pyriformis proteinases.

\section{METHODS}

Chemicals and reagents. PMSF and Folin-Ciocalteu reagent were purchased from BDH, and leupeptin, antipain, chymostatin and pepstatin from the Protein Research Foundation, Osaka, Japan. All other fine chemicals, including substrates, were from Sigma. Neopeptone was obtained from Difco and neutralized liver digest from Oxoid. All other chemicals and reagents were of the highest purity commercially available.

Organism and culture conditions. Tetrahymena pyriformis GL (Culture Centre of Algae and Protozoa CCAP 1630/1f) was obtained from Dr G. H. Coombs, Glasgow University, UK. It was grown axenically in NPLD medium $[2 \%(w / v)$ neopeptone and $0.1 \%(w / v)$ neutralized liver digest $]$ at $28{ }^{\circ} \mathrm{C}$, normally with shaking (100 r.p.m.) in an orbital incubator. In most experiments the cells were grown in $500 \mathrm{ml}$ batches of medium in 2 litre Erlenmeyer flasks. Cell density was determined using a haemocytometer. Unless otherwise indicated cells were inoculated at a density of approximately $10^{3} \mathrm{cells} \mathrm{ml}^{-1}$ and harvested after $72 \mathrm{~h}$ when the cells had entered the transition phase of the growth cycle $\left(2-3 \times 10^{5}\right.$ cells ml $\left.^{-1}\right)$. Before harvesting, the cells were rapidly chilled and were then centrifuged for $3 \mathrm{~min}$ at $4{ }^{\circ} \mathrm{C}$ and $200 \mathrm{~g}$ (Klemperer \& Pllley, 1982). The cells were then washed twice by resuspending in ice-cold $0.2 \mathrm{M}$-potassium phosphate buffer, $\mathrm{pH} 7 \cdot 2$, containing $0.1 \mathrm{M}-\mathrm{NaCl}$, and centrifuging as above. The cells were resuspended in small volumes (approximately $1 \mathrm{ml}$ per $200 \mathrm{ml}$ original culture) of the above buffer and frozen immediately. The cells were lysed by two cycles of freezing and thawing and finally by adding $0 \cdot 1 \%(\mathrm{v} / \mathrm{v})$ Triton $\mathrm{X}-100$.

For transfer to fresh medium or starvation buffer $(0.01 \mathrm{M}$-Tris/ $\mathrm{HCl}, \mathrm{pH} 7.5)$ cells were harvested by centrifugation as above, and after removal of the orginal medium by decanting were immediately resuspended in the new medium at the original density. Incubation was then continued with shaking as described above.

Enzyme assays. All assays were carried out at $30^{\circ} \mathrm{C}$. Proteinase activity towards HPA was determined as described previously (North \& Whyte, 1984). For the standard assay conditions the buffers were $0.1 \mathrm{M}$-sodium acetate/acetic acid, $\mathrm{pH} 4.0$ and $0.1 \mathrm{M}-\mathrm{Tris} / \mathrm{HCl}, \mathrm{pH} 8.0$, and $0.01 \mathrm{ml} 0.1 \mathrm{M}-\mathrm{DTT}$ was included in the standard assay mixtures.

The assay method using AZC was modified from that of Levy et al. (1976) so that the conditions were equivalent to those used with HPA. The assay mixture contained $0.5 \mathrm{ml}$ buffer (for standard assay conditions $0 \cdot 1 \mathrm{M}$ - Tris/ $\mathrm{HCl}$, $\mathrm{pH} 8.0), 0.5 \mathrm{ml} \mathrm{AZC}\left(10 \mathrm{mg} \mathrm{ml}^{-1}\right)$ and when required $0.01 \mathrm{ml} 0.1 \mathrm{M}$-DTT. The reaction was started by addition of up to $0.1 \mathrm{ml}$ sample and stopped with $0.2 \mathrm{ml} 50 \%(\mathrm{w} / \mathrm{v})$ TCA. The precipitate was removed by centrifugation $(13400 \mathrm{~g}, 5 \mathrm{~min})$ and the supernatant was made alkaline by addition of $0.2 \mathrm{ml} 4 \mathrm{M}-\mathrm{NaOH}$. The absorbance at $520 \mathrm{~nm}$ was read. Under these conditions an absorbance increase of 1.0 was equivalent to the hydrolysis of $0.71 \mathrm{mg}$ AZC.

Activity towards the peptide nitroanilides and Bz-Arg-Nan was measured by a method adapted from that used previously (North \& Whyte, 1984), but because the lysates of $T$. pyriformis were too cloudy it was not possible to use a continuous assay. The assay mixture contained $0.5 \mathrm{ml}$ buffer (for standard assay conditions $0.1 \mathrm{M}$-sodium phosphate, $\mathrm{pH} 7.0$ ), $0.01 \mathrm{ml} \mathrm{0.1} \mathrm{M-DTT,} 0.05 \mathrm{ml}$ sample and $0.025 \mathrm{ml} 1 \mathrm{mM}$-substrate. The reaction was stopped by the addition of $0.1 \mathrm{ml} \mathrm{50 \%}(\mathrm{w} / \mathrm{v})$ TCA and the precipitate removed by centrifugation $(13400 \mathrm{~g}, \mathrm{l} \mathrm{min})$. A $0.4 \mathrm{ml}$ sample of supernatant was added to $0.6 \mathrm{ml} 1 \mathrm{M}-\mathrm{Na}_{2} \mathrm{CO}_{3}$ and the absorbance at $405 \mathrm{~nm}$ was read.

Proteolytic activities are expressed as $\mu \mathrm{g}$ protein hydrolysed $\min ^{-1}$ (for HPA and AZC) or nmol nitroaniline released $\min ^{-1}$ (for peptide nitroanilides and Bz-Arg-Nan). Specific activity is expressed as units of activity (mg protein $)^{-1}$. Protein was determined by the method of Sedmak \& Grossberg (1977) except with the samples from sucrose density gradients when the Lowry method was used. Bovine albumin (fraction V) was used as standard.

NADP-dependent isocitrate dehydrogenase (EC 1.1.1.42) was determined by the following method. An assay mixture was prepared containing $0.05 \mathrm{ml} 2 \%(\mathrm{v} / \mathrm{v})$ Triton X-100;0.3 ml 0.1 M-Tris/HCl, $\mathrm{pH} 7.5 ; 0.03 \mathrm{ml} 0.02 \mathrm{M}-$ $\mathrm{MnCl}_{2} ; 0.02 \mathrm{ml}$ NADP $\left(4 \mathrm{mg} \mathrm{ml}^{-1}\right) ; 0.9 \mathrm{ml}$ water and up to $0.05 \mathrm{ml}$ sample. A sample $(0.35 \mathrm{ml})$ of this solution was transferred to each of two matched cuvettes to which $0.01 \mathrm{ml} 0.01 \mathrm{M}-\mathrm{D}, \mathrm{L}$-isocitric acid and $0.01 \mathrm{ml}$ water had been added, respectively. The increase in absorbance at $340 \mathrm{~nm}$ was followed in a Varian 634 double beam spectrophotometer. All other enzymes were assayed by published methods: acid phosphatase (EC 3.1 . 3.2; Levy \& Elliott, 1968), $N$-acetylglucosaminidase (EC 3.2.1.30; Loomis, 1969) and succinate dehydrogenase [succinate2-(p-iodophenyl)-3-( $p$-nitrophenyl)-5-phenyltetrazolium reductase, EC 1.3.99.1; Pennington, 1961]. 
Treatment with proteinase inhibitors. To test the effect of inhibitors, samples of cell lysate were preincubated for $1 \mathrm{~h}$ at room temperature as described previously (North et al., 1983). Control samples were incubated identically but without inhibitor.

Fractionation of proteinases by ion-exchange chromatography. Proteinase fractions were separated on DEAEcellulose as described by Banno et al. (1982), except that only $\left(\mathrm{NH}_{4}\right)_{2} \mathrm{SO}_{4}$ fractionation of their preceding purification steps was retained. This abbreviated procedure does not affect the proteinase separation (Banno $e t$ al., 1982). The protein precipitated from cell lysates by $\left(\mathrm{NH}_{4}\right)_{2} \mathrm{SO}_{4}$ between $30 \%$ and $60 \%$ saturation was collected by centrifugation at $26000 \mathrm{~g}$ for $10 \mathrm{~min}$ at $4^{\circ} \mathrm{C}$ and dissolved in $0.01 \mathrm{M}$-potassium phosphate buffer, pH 6.7. The sample was then dialysed against the same buffer and applied to a column $(75 \times 23 \mathrm{~mm})$ of DEAE-cellulose (Whatman DE-52) previously equilibrated with buffer. Fractions $(3 \mathrm{ml})$ were collected. Those containing proteinase activity analogous to fractions P-I, P-II and P-IV (Banno et al., 1982) were collected immediately and after application of buffer containing $0.1 \mathrm{M}-\mathrm{KCl}$ and $0.3 \mathrm{M}-\mathrm{KCl}$, respectively.

Subcellular fractionation. The procedure was based on that of Levy et al. (1976). Washed cells were homogenized in $0.25 \mathrm{M}$-sucrose and the fluffy layer (Pf) and tightly packed layer (Pt) collected by centrifugation at $2000 \mathrm{~g}$ for $10 \mathrm{~min}$ at $4^{\circ} \mathrm{C}$. Discontinuous sucrose gradients were prepared in $61 \times 12 \mathrm{~mm}$ centrifuge tubes with $1 \mathrm{ml}$ layers of $2 \cdot 1,1 \cdot 8,1 \cdot 5,1.2$ and $0.9 \mathrm{M}$-sucrose. A $1 \mathrm{ml}$ sample of Pf or Pt was layered on the top of each gradient and the tubes were spun at $71000 \mathrm{~g}$ for $50 \mathrm{~min}$ at $4{ }^{\circ} \mathrm{C}$. Six fractions were removed from the gradient so that they contained discrete bands, and material pelleted at the bottom of the tube was resuspended in $1 \mathrm{ml} 0.25 \mathrm{M}$-sucrose (fraction 7 ). Enzyme assays were carried out as described above except that the sample was incubated with assay buffer and $0 \cdot 1 \%(v / v)$ Triton $X-100$ for 5 min before the assay was started.

Electrophoretic analysis. The proteinases in cell lysates were analysed by PAGE using haemoglobin-containing gels as described previously (North \& Coombs, 1981). AZC-containing gels were prepared in the same way as haemoglobin gels except that the AZC solution was not heated or sonicated. AZC gels were stained with Coomassie Brilliant Blue R250 (1.25 g in $227 \mathrm{ml}$ methanol, $46 \mathrm{ml}$ glacial acetic acid and $227 \mathrm{ml}$ water) and destained in methanol/glacial acetic acid/water $(1: 1 \cdot 5: 17 \cdot 5$, by vol.). All gels were scanned at $550 \mathrm{~nm}$ using a Gelman DCD-16 scanner.

\section{RESULTS AND DISCUSSION}

\section{Proteolytic activities detected and their properties}

The substrates used in this study were the proteins HPA and AZC, and the nitroanilide BzArg-Nan and related peptide nitroanilides. Of these only AZC and Bz-Arg-Nan had previously been used for $T$. pyriformis proteinases. HPA was, in many respects, a better substrate than AZC. It is particulate and is in the same physical state irrespective of $\mathrm{pH}$. In contrast AZC is soluble above $\mathrm{pH} 4.5$ but precipitates in more acid solutions. This complicates any comparisons between activity at different $\mathrm{pHs}$. A further advantage with HPA is that during an assay it is easy to observe hydrolysis without the need to stop the reaction. HPA was more rapidly hydrolysed than AZC. Both HPA and AZC were hydrolysed over a wide range of pH (Fig. 1). For HPA the maximum activity was at $\mathrm{pH} \mathrm{4-5,} \mathrm{but} \mathrm{a} \mathrm{second} \mathrm{activity} \mathrm{was} \mathrm{indicated} \mathrm{by} \mathrm{the}$ shoulder in the slightly alkaline range. At all $\mathrm{pH}$ values except $\mathrm{pH} 10$ the activity was stimulated by 1 mM-DTT. Similar results were obtained with AZC except that the degree of hydrolysis at acid $\mathrm{pH}$ values was very variable, probably due to the effect of precipitation. The specific activity for the hydrolysis of HPA at $\mathrm{pH} 4$ compared well with that reported with haemoglobin as substrate (Müller et al., 1966; Müller, 1972) whilst the specific activity towards AZC was similar to that reported by others (Suprynowicz \& Allewell, 1979; Banno et al., 1982, 1983).

Bz-Arg-Nan has been used by Banno et al. (1982) as a substrate for T. pyriformis proteinases. However, studies of other eukaryotic micro-organisms have shown that peptide nitroanilides are better substrates (North et al., 1983; North \& Whyte, 1984). This was also so for $T$. pyriformis. For lysates prepared from $2 \mathrm{~d}$ cultures the activities measured at $\mathrm{pH} 7$ in the presence of $1 \mathrm{mM}$ DTT were 15·5-, 35·0-, 55.5- and 109-fold greater than with Bz-Arg-Nan for Bz-Val-Gly-ArgNan, Bz-Phe-Val-Arg-Nan, Tos-Gly-Pro-Arg-Nan and Bz-Pro-Phe-Arg-Nan, respectively. Omission of DTT decreased these activities by $48 \%, 64 \%, 77 \%$ and $78 \%$, respectively, and the activity toward Bz-Arg-Nan was below the limit of detection. The activity towards both Tos-Gly-Pro-Arg-Nan and Bz-Pro-Phe-Arg-Nan was maximal at pH 7 (Fig. 1).

For further analysis five assay conditions were selected. To allow comparison with the data of other workers, neutral proteinase activity was assayed at $\mathrm{pH} 8$ with $\mathrm{AZC}$, and in order to compare neutral and acid proteinase activity HPA was used at two $\mathrm{pH}$ values, 4 and 8 , the latter 


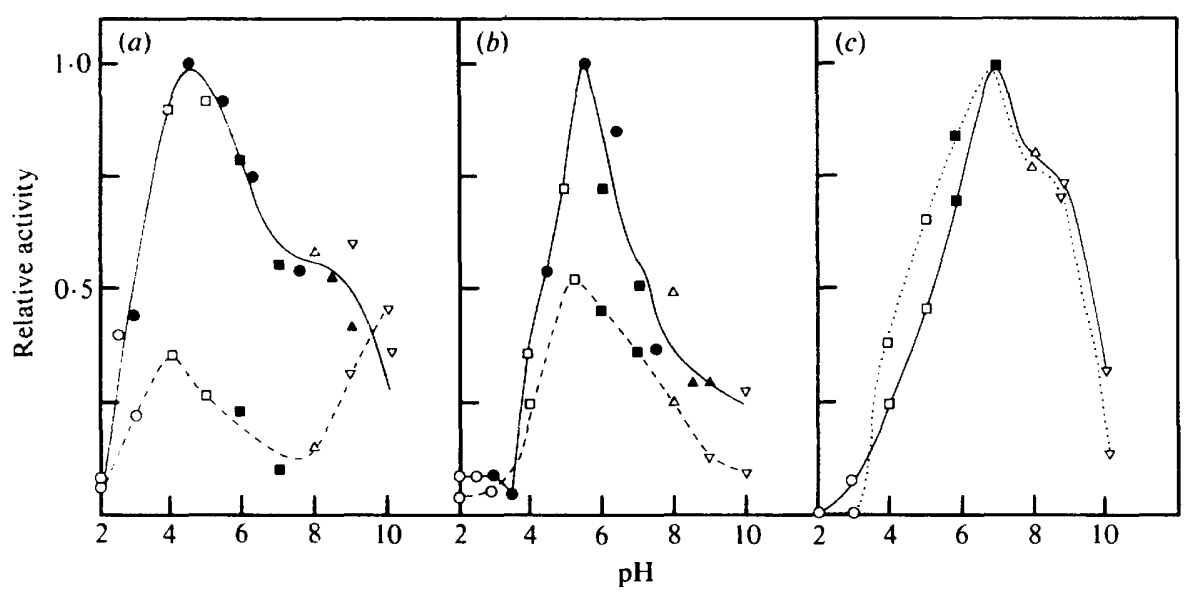

Fig. 1. Influence of pH on proteolytic activities. Substrates: (a) HPA, (b) AZC, (c) Bz-Pro-Phe-ArgNan $(-)$ and Tos-Gly-Pro-Arg-Nan (…). With HPA and AZC as substrates activity was determined both in the presence $(-)$ and absence (---) of 1 mM-DTT. With the nitroanilides as substrate $1 \mathrm{mM}$-DTT was always included. Buffers: $0 \cdot 1 \mathrm{M}$-glycine/ $\mathrm{HCl}(\mathrm{O})$, McIlvaine's buffer $(0 \cdot 1 \mathrm{M}$ citric acid $\left./ 0 \cdot 2 \mathrm{M}-\mathrm{Na}_{2} \mathrm{HPO}_{4}\right)(\bigcirc), 0 \cdot 1 \mathrm{M}$-sodium acetate/acetic acid $(\square), 0 \cdot 1 \mathrm{M}$-sodium phosphate ( $\square$ ), $0.1 \mathrm{M}-\mathrm{Tris} / \mathrm{HCl}(\Delta), 0.1 \mathrm{M}$-bicine $/ \mathrm{NaOH}(\Delta)$ and $0.1 \mathrm{M}$-glycine $/ \mathrm{NaOH}(\nabla)$. Activities are given relative to the maximum activity (1.0) which were for HPA, $49.2 \mu \mathrm{g}$ hydrolysed $\min ^{-1}(\mathrm{mg} \text { protein })^{-1}$; for AZC, $5.87 \mu \mathrm{g}$ hydrolysed $\mathrm{min}^{-1}$ (mg protein) ${ }^{-1}$; for Bz-Pro-Phe-Arg-Nan, $5.40 \mathrm{nmol} \mathrm{min}^{-1}$ (mg protein) ${ }^{-1}$; and for Tos-Gly-Pro-Arg-Nan, $1.85 \mathrm{nmol} \mathrm{min}^{-1}$ (mg protein) ${ }^{-1}$.

\section{Table 1. Effect of inhibitors on proteolytic activities}

Activity remaining $(\%)^{*}$ :

Inhibitor Concn HPA, pH 4 HPA, pH 8 AZC Bz-Pro-Phe-Arg-Nan Tos-Gly-Pro-Arg-Nan

\begin{tabular}{|c|c|c|c|c|c|c|}
\hline Pepstatin & $0.1 \mathrm{mg} \mathrm{ml}^{-1}$ & $96 \cdot 1$ & 104 & $90 \cdot 5$ & $87 \cdot 6$ & $88 \cdot 6$ \\
\hline Chymostatin & $0.1 \mathrm{mg} \mathrm{mi}^{-1}$ & 74.6 & 33.6 & $20 \cdot 3$ & $28 \cdot 1$ & $2 \cdot 1$ \\
\hline Leupeptin & $0.1 \mathrm{mg} \mathrm{ml}^{-1}$ & $52 \cdot 9$ & 8.4 & $12 \cdot 8$ & 16.9 & 0 \\
\hline Antipain & $0.1 \mathrm{mg} \mathrm{ml}^{-1}$ & $26 \cdot 0$ & $5 \cdot 4$ & 13.8 & $26 \cdot 5$ & $8 \cdot 2$ \\
\hline Iodoacetic acid & $1 \mathrm{~mm}$ & 19.9 & $18 \cdot 6$ & $10 \cdot 7$ & $27 \cdot 4$ & $6 \cdot 0$ \\
\hline TLCK & $1 \mathrm{mM}$ & $15 \cdot 3$ & $17 \cdot 4$ & $5 \cdot 6$ & $21 \cdot 3$ & 17 \\
\hline Phenanthroline & $1 \mathrm{mM}$ & 54.8 & $96 \cdot 6$ & $62 \cdot 7$ & $62 \cdot 6$ & 14 \\
\hline TPCK & $1 \mathrm{mM}$ & 100 & 101 & $79 \cdot 0$ & 128 & 100 \\
\hline PMSF & $1 \mathrm{mM}$ & 101 & 108 & 87.6 & 107 & 100 \\
\hline
\end{tabular}

* Activities are given as a percentage of that in control samples, which were 45.8, 35.3 and $3.09 \mu \mathrm{g}$ hydrolysed $\min ^{-1}$ (mg protein) ${ }^{-1}$ for HPA, pH 4, HPA, pH 8 and AZC, respectively, and 2.91 and $0.43 \mathrm{nmol} \mathrm{min}^{-1}\left(\mathrm{mg}^{-1}\right.$ protein) ${ }^{-1}$ for Bz-Pro-Phe-Arg-Nan and Tos-Gly-Pro-Arg-Nan, respectively. The results are the average from two independent determinations.

allowing a direct comparison with AZC. Two nitroanilides were chosen, Bz-Pro-Phe-Arg-Nan and Tos-Gly-Pro-Arg-Nan, since in trypanosomes there are differences between the activities detected (North et al., 1983), and these were used at $\mathrm{pH} 7$. All five activities were measured in the presence of DTT. In cell lysates they were all stable during storage for $24 \mathrm{~h}$ at $-15^{\circ} \mathrm{C}, 4{ }^{\circ} \mathrm{C}$ and $30^{\circ} \mathrm{C}$.

The effects of proteinase inhibitors are shown in Table 1. None of the activities was affected by the aspartic proteinase inhibitor pepstatin nor by the serine proteinase inhibitor, PMSF. TPCK, a chymotrypsin inhibitor which also inactivates some cysteine proteinases, also lacked effect, although there have been reports of severe inhibition of $T$. pyriformis proteinases by this agent (Levy et al., 1976; Banno et al., 1983). All the activities were inhibited to some extent by chymostatin, leupeptin, antipain, iodoacetic acid and TLCK. Each of these agents has been shown to inhibit a number of cysteine proteinases. The degree of effect was similar for the four neutral proteinase activities (HPA, pH 8, AZC, Bz-Pro-Phe-Arg-Nan and Tos-Gly-Pro-Arg- 
Table 2. Proteolytic activities in fractions separated by chromatography on DEAE-cellulose

A sample prepared by $\left(\mathrm{NH}_{4}\right)_{2} \mathrm{SO}_{4}$ fractionation as described in Methods was applied to a column of DEAE-cellulose and fractions collected before and after elution with $\mathrm{KCl}$. The results are those for the fraction containing the highest activity.

\begin{tabular}{|c|c|c|c|c|c|}
\hline \multirow{2}{*}{$\begin{array}{l}\text { Concn of } \mathrm{KCl} \\
\text { for elution }(\mathrm{M})\end{array}$} & \multicolumn{3}{|c|}{$\begin{array}{c}\text { Specific activity } \\
{\left[\mu \mathrm{g} \text { hydrolysed } \min ^{-1}(\mathrm{mg} \text { protein })^{-1}\right]}\end{array}$} & \multicolumn{2}{|c|}{$\begin{array}{c}\text { Specific activity } \\
{\left[\mathrm{nmol} \min ^{-1}(\mathrm{mg} \text { protein })^{-1}\right]}\end{array}$} \\
\hline & HPA, pH 4 & HPA, pH 8 & $\mathrm{AZC}$ & Bz-Pro-Phe-Arg-Nan & Tos-Gly-Pro-Arg-Nan \\
\hline 0 & $21 \cdot 8$ & $21 \cdot 4$ & $2 \cdot 04$ & ND & $0 \cdot 30$ \\
\hline $0 \cdot 1$ & $28 \cdot 6$ & 14.8 & 0.80 & 0.72 & 1.00 \\
\hline 0.3 & $86 \cdot 6$ & $32 \cdot 2$ & $2 \cdot 86$ & $27 \cdot 9$ & $4 \cdot 46$ \\
\hline
\end{tabular}

ND, Not detectable: limit of detection $0.20 \mathrm{nmol}$ nitroaniline released $\mathrm{min}^{-1}$ (mg protein) ${ }^{-1}$.

\section{Table 3. Effect of culture age on proteinase specific activity}

Cultures of $T$. pyriformis were grown with shaking unless indicated and harvested at different times after inoculation for cell lysate preparation and enzyme activity determination. The results are the mean values from the number of determinations indicated in parentheses and are given $\pm S D$. Units are given in Table 2.

\begin{tabular}{|c|c|c|c|c|c|}
\hline \multirow{2}{*}{$\begin{array}{l}\text { Culture age } \\
\text { (d) }\end{array}$} & \multicolumn{5}{|c|}{ Specific activity } \\
\hline & HPA, pH 4 & HPA, pH 8 & AZC & Bz-Pro-Phe-Arg-Nan & Tos-Gly-Pro-Arg-Nan \\
\hline 1 & $12 \cdot 7 \pm 1 \cdot 2$ & ND & $0.15 \pm 0.13$ & $1 \cdot 12 \pm 0.35$ & $0.68 \pm 0.40$ \\
\hline 2 & $42 \cdot 8 \pm 14.9$ & $18 \cdot 3 \pm 9 \cdot 2$ & $1.97 \pm 0.77$ & $3.00 \pm 1.02$ & $0.88 \pm 0.74$ \\
\hline 3 & $48.2 \pm 19.2(12)$ & $31.8 \pm 10.8(10)$ & $3.82 \pm 2.05(12)$ & $4.72 \pm 1.67(11)$ & $1.25 \pm 0.98(11)$ \\
\hline 5 & $54 \cdot 5 \pm 11 \cdot 4$ & $56.9 \pm 21.9$ & $4 \cdot 10 \pm 1 \cdot 10$ & $5.66 \pm 0.32$ & $0.46 \pm 0.04$ \\
\hline 5 , not shaken & $66.4 \pm 8.6$ & $70 \cdot 0 \pm 8 \cdot 1$ & $4.29 \pm 0.25$ & $7 \cdot 15 \pm 0.22$ & $0.23 \pm 0.07$ \\
\hline
\end{tabular}

Nan), although the activity towards the latter substrate was in general more severely inhibited. The acid proteinase activity (HPA, $\mathrm{pH} 4$ ) was less sensitive to antipain, leupeptin and chymostatin. While these results suggest that all of the activities were due to cysteine proteinases, they differ from those of others who found that chymostatin was a better inhibitor than leupeptin and antipain (Blum, 1975; Levy et al., 1976). Phenanthroline, which inhibits cysteine proteinases in other protozoa (North \& Coombs, 1981; Coombs \& North, 1983; North et al., 1983), had some effect on most of the activities.

\section{Fractionation by ion-exchange chromatography}

Ion-exchange chromatography has been used to separate different proteinase fractions from $T$. pyriformis. Using the procedure of Banno et al. (1982) it was possible to demonstrate three of the fractions they found, P-I, P-II and P-IV (Table 2), although we were unable to resolve a fourth proteinase fraction, P-III, reported to be eluted by $0 \cdot 1 \mathrm{M}-\mathrm{KCl}$ after fraction P-II. Similar values for the specific activity towards AZC were found in the three fractions and the distribution of the neutral activity towards HPA was similar. However, the activity towards the peptide nitroanilides was greater in P-IV than in the other fractions and activity towards BzPro-Phe-Arg-Nan could not be detected in P-I. This difference in specificity was also observed by Banno et al. (1982) who used AZC and Bz-Arg-Nan. The specific activity of the acid proteinase was highest in P-IV and therefore differed from that of the activity towards HPA at $\mathrm{pH} 8$.

\section{Changes in intracellular proteolytic activity}

The intracellular activities of a number of hydrolytic enzymes in $T$. pyriformis change during the growth cycle (Blum \& Rothstein, 1975). Although there was some variation in the activity in different cultures of similar age there was in general an increase in all specific activities during the exponential (1-2d) and transition phase (3d) of growth (Table 3). However, while the 

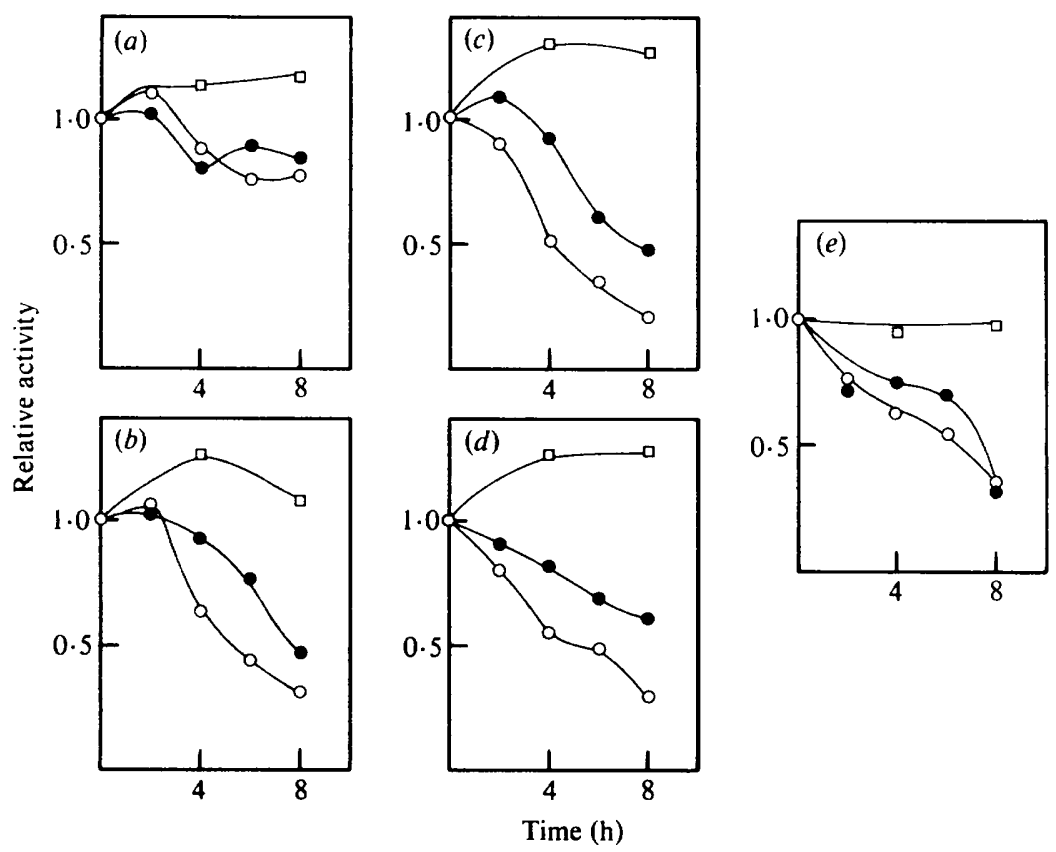

Fig. 2. Effect of starvation and resuspension in fresh medium on proteolytic activities. Cells were centrifuged and resuspended as described in Methods in either $0.01 \mathrm{M}$ - Tris/ $/ \mathrm{HCl}, \mathrm{pH} 8.0(\mathrm{O})$, fresh medium (O) or the original medium from which they were harvested $(\square)$. Substrates: (a) HPA, pH 4 [initial specific activity $29.8 \mu \mathrm{g}$ hydrolysed $\min ^{-1}(\mathrm{mg} \text { protein })^{-1}$ ]; (b) HPA, pH 8 [20.9 $\mu \mathrm{g}$ hydrolysed

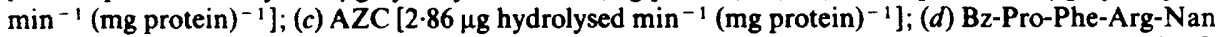
[2.48 $\mathrm{nmol} \mathrm{min}^{-1}$ (mg protein) $\left.{ }^{-1}\right]$; (e) Tos-Gly-Pro-Arg-Nan [0.83 nmol min ${ }^{-1}$ (mg protein) $\left.)^{-1}\right]$. Specific activities are given relative to this initial value.

increase in acid proteinase activity was confined to early growth the neutral proteinase activities increased during the later stages. This could be seen from changes in the profile of the $\mathrm{pH}$ dependence curve for activity towards HPA. Slightly higher activities were found in stationary phase ( $5 \mathrm{~d}$ ) cultures with the exception of the activity towards Tos-Gly-Pro-Arg-Nan for which there was greatest variation between similar cultures. The activity in $5 \mathrm{~d}$ cultures was not significantly affected by the degree of aeration of the culture. The results for neutral activity with AZC as substrate may be compared with those of Suprynowicz \& Allewell (1979) who reported a similar increase as cultures aged, but they differ from the changes reported by Banno et al. (1982) in cultures of WH-14 cells for which a decrease in intracellular activity was recorded. The difference might be due to strain differences or variations in culture conditions.

Nutrient deprivation results in a decline in the intracellular activity of neutral proteinase (AZC, pH 8) (Suprynowicz \& Allewell, 1979) and so the effect of this treatment was tested on all five activities (Fig. 2). There was a rapid decline in the four neutral activities on resuspension in Tris buffer. In contrast, the acid proteinase activity (HPA, pH 4) decreased only slightly. Suprynowicz \& Allewell (1979) described a factor in the medium responsible for inducing intracellular proteinase activity in stationary phase cells. Since this factor would be lacking from fresh medium we tested the effect of resuspending cells in fresh medium. The effect was similar to that found for nutrient deprivation with a much smaller effect on the acid proteinase activity than on the neutral activities. There was little change in any of the activities if the cells were resuspended in the original medium and so none of the changes could be attributed simply to the perturbation caused by chilling and centrifugation.

In view of the difference between the acid and neutral activities it is of interest to note that Levy et al. (1976) reported much smaller changes in the level of acid proteinase activity (haemoglobin, $\mathrm{pH} \mathrm{3.6)}$ than that of neutral proteinase activity (AZC, $\mathrm{pH} \mathrm{8)}$ on shaking previously standing cultures. The relatively small decline in acid proteinase activity upon 


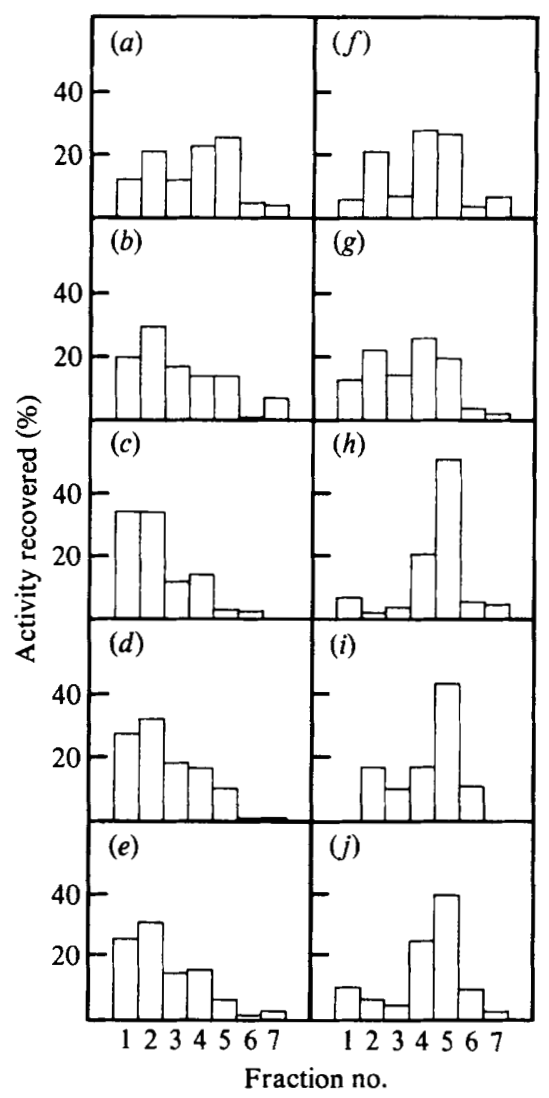

Fig. 3. Analysis of $P f$ fraction on sucrose density gradients. Fraction 1 corresponds to the position of the loaded sample. Fractions 2-6 correspond to sucrose densities of $1 \cdot 12,1 \cdot 16,1 \cdot 19,1.23$ and $1.27 \mathrm{~g} \mathrm{l}^{-1}$, respectively. Fraction 7 contains resuspended material pelleted during centrifugation. The activity in each fraction is given as a percentage of the total recovered. $(a-e)$ Proteolytic activities with the following substrates: (a) HPA, pH 4; (b) HPA, pH 8; (c) AZC; (d) Bz-Pro-Phe-Arg-Nan; (e) Tos-GlyPro-Arg-Nan; $(f)$ acid phosphatase; $(g) N$-acetylglucosaminidase; $(h)$ isocitrate dehydrogenase; $(i)$ succinate dehydrogenase; $(j)$ protein.

nutrient deprivation might be related to a lack of release of enzyme into the buffer. Müller (1972) reported that only a negligible proportion of the proteinase activity towards haemoglobin (pH 3.4) was released, although Blum $(1975,1976)$ has described acid proteinase release.

\section{Subcellular localization}

Much of the proteinase activity of $T$. pyriformis is localized within subcellular particles (Müller, 1972; Levy et al., 1976; Blum, 1976; Banno et al., 1982). To determine whether the different behaviour of the activities on nutrient deprivation might be a consequence of differences in subcellular localization a discontinuous sucrose density gradient analysis was carried out. Figure 3 shows an analysis of the Pf fraction in which major bands of particulate material were recovered in fractions 2,4 and 5 . The $P t$ fraction gave much smaller amounts of material in fractions 2 and 4 but similar conclusions could be drawn to those from the Pf data. The position of the marker enzymes acid phosphatase, $N$-acetylglucosaminidase, isocitrate dehydrogenase and succinate dehydrogenase were essentially those expected from previous studies (Müller et al., 1966; Lloyd et al., 1971; Blum, 1976; Levy et al., 1976). A difference in the localization of proteinase activities was apparent. The acid proteinase activity had a similar distribution to that of $\mathrm{N}$-acetylglucosaminidase, which agrees with the observations of Blum (1976). All four neutral activities had a similar distribution to one another but one which did not 


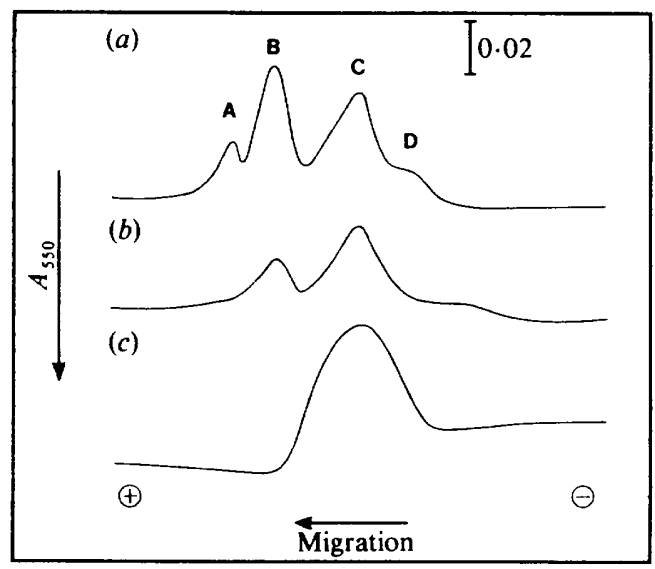

Fig. 4. Proteinase band patterns on polyacrylamide gels. Gels were loaded with cell lysate containing $300 \mu \mathrm{g}$ protein. (a) Gel containing haemoglobin incubated at $\mathrm{pH} 4$ in the presence of $1 \mathrm{mM}-\mathrm{DTT} ;(b)$ gel containing haemoglobin incubated at $\mathrm{pH} \mathrm{4;} \mathrm{(c)} \mathrm{gel} \mathrm{containing} \mathrm{AZC} \mathrm{incubated} \mathrm{at} \mathrm{pH} 6$ in the presence of $1 \mathrm{~mm}$-DTT. The scans represent complete gels.

match that of any of the other enzymes. A much higher proportion of the activity was recovered from the lighter portions of the gradient. Some acid phosphatase was present in fraction 2 which might suggest that some of the neutral proteinase activity was present within a sub-population of low density lysosomes. In their analysis Levy et al. (1976) also demonstrated differences in the distribution of the various proteinase activities.

\section{Electrophoretic analysis}

In other protozoan species it has been possible to detect mutiple forms of proteinase by PAGE using gels containing denatured haemoglobin (North \& Coombs, 1981 ; Coombs \& North, 1983; North et al., 1983). Since these proteinases, like those of $T$. pyriformis, were cysteine proteinases we examined the suitability of this method for analysing the enzymes of $T$. pyriformis. With many lysates it was possible to see multiple proteinase bands, but the method proved less reliable than with other species. Figure 4 shows the position of the four bands that were detected. The presence of DTT was essential for the appearance of bands A and D and enhanced the appearance of bands $\mathrm{B}$ and $\mathrm{C}$. There was some evidence that the proteinases responsible for bands $A$ and $D$ were present only during the late exponential phase of growth. However, they were not observed consistently. The development of the proteinase bands was improved if lysates were spun briefly in a micro-centrifuge to remove particulate material. Bands developed most rapidly at $\mathrm{pH} 4$ and did not form at $\mathrm{pH}$ values above 6 . It was not possible to test at lower pHs because of difficulties with the solubilization of haemoglobin which occurred during long incubation at acid pH. Development of bands $\mathrm{B}$ and $\mathrm{C}$ in gels was inhibited by treatment with $100 \mu \mathrm{g}$ antipain $\mathrm{ml}^{-1}, 1 \mathrm{~mm}$-iodoacetic acid and $1 \mathrm{mM}$-TLCK. Their appearance was decreased by $1 \mathrm{~mm}$-phenanthroline and by chymostatin and leupeptin (both at $100 \mu \mathrm{g} \mathrm{ml}^{-1}$ ). Pepstatin, TPCK and PMSF had no effect. These results suggest that the proteinases responsible for bands $\mathrm{B}$ and $\mathrm{C}$ were probably responsible for hydrolysis of HPA at $\mathrm{pH} 4$.

It was also possible to detect a single proteinase band on gels containing AZC. This band formed at a position corresponding to proteinase $\mathrm{C}$ but its development was optimal at $\mathrm{pH} 6$ and activity was still detected at both pH 4 and 8 . The effect of inhibitors was not tested.

\section{Comparison between proteolytic activities}

Many of the observations reported here confirm results published previously by other workers. Their importance is in the fact that the choice of assay conditions has allowed comparisons to be made between the proteolytic activities which have not always been attempted in the past. Acid proteinase and neutral proteinases were shown to be different from 
one another not only in terms of inhibitor sensitivity but more clearly in the differences found in the response of intracellular activities to growth and starvation and in subcellular localization. The use of HPA for both acid and neutral activities has eliminated the possibility that differences were the result of varying the substrate. The results obtained for activity towards HPA at pH 8 were very similar to those for activity towards AZC and it seems likely that the two methods were measuring the same enzyme(s). Because it can be used for comparisons with acid proteinase activity, we would recommend the use of HPA to assay neutral activity as well. The variations amongst the neutral proteinase activities have also been confirmed (Table 2), although the multiple forms appear to be subject to similar physiological control and are apparently localized within the same subcellular fractions. Since Bz-Pro-Phe-Arg-Nan was a better substrate than Bz-Arg-Nan it should prove to be more useful for assaying the P-IV type of proteinase, especially as the P-I type appeared to have very little activity towards it. Some differences between the activity towards Bz-Pro-Phe-Arg-Nan and Tos-Gly-Pro-Arg-Nan were apparent but would need to be investigated in more detail to determine whether the latter would be suitable for assaying particular types of proteinase. Whilst none of the assay conditions is necessarily absolutely specific for one form of proteinase, their use should help in further studies of the Tetrahymena proteolytic system.

\section{REFERENCES}

Banno, Y., Yano, K. \& Nozawa, Y. (1982). Biochemical characterization of secreted proteases during growth in Tetrahymena pyriformis WH-14: comparison of extracellular with intracellular proteases. Journal of Protozoology 29, 91-98.

Banno, Y., Yano, K. \& Nozawa, Y. (1983). Purification and characterization of a secreted protease from Tetrahymena pyriformis. European Journal of Biochemistry 132, 563-568.

BLUM, J. J. (1975). Effects of metabolites present during growth of Tetrahymena pyriformis on the subsequent secretion of lysosomal hydrolases. Journal of Cellular Physiology 86, 131-142.

BLUM, J. J. (1976). Lysosomal hydrolase secretion by Tetrahymena: a comparison of several intralysosomal enzymes with the isoenzymes released into the medium. Journal of Cellular Physiology 89, 457472.

Blum, J. J. \& RothsteIN, T. L. (1975). Lysosomes in Tetrahymena. In Lysosomes in Biology and Pathology, vol. 4, pp. 33-45. Edited by J. T. Dingle \& R. T. Dean. Amsterdam: North-Holland.

COOMBS, G. H. \& NoRTH, M. J. (1983). An analysis of the proteinases of Trichomonas vaginalis by polyacrylamide gel electrophoresis. Parasitology 86, 1-6.

DICKIE, N. \& LIENER, I. E. (1962). A study of the proteolytic system of Tetrahymena pyriformis $\mathrm{W}$. I. Purification and partial characterization of the constituent proteinases. Biochimica et biophysica acta 64, 41-51.

KLemperer, H. G. \& Pilley, D. J. (1982). The breakdown of Tetrahymena ribosomes in vivo. The effects of inhibitors. Biochemical Journal 208, 831-837.

LEVy, M. R. \& Elliot, A. M. (1968). Biochemical and ultrastructural changes in Tetrahymena pyriformis during starvation. Journal of Protozoology 15, 208222.

Levy, M. R., Sissinin, E. E. \& McConkey, C. L. (1976). A protease that increases during a period of enzymic and metabolic adjustment in Tetrahymena. Archives of Biochemistry and Biophysics 172, 634647.
Lloyd, D., BRightwell, R., Venables, S. E., Roach, G. I. \& TURNER, G. (1971). Subcellular fractionation of Tetrahymena pyriformis ST by zonal centrifugation: changes in activities and distribution of enzymes during the growth cycle and on starvation. Journal of General Microbiology 65, 209-223.

LoOMIs, W. F. (1969). Acetylglucosaminidase, an early enzyme in the development of Dictyostelium discoideum. Journal of Bacteriology 97, 1149-1154.

MüLLER, M. (1972). Secretion of acid hydrolases and its intracellular source in Tetrahymena pyriformis. Journal of Cell Biology 52, 478-487.

Müller, M., Baudhuin, P. \& DE Duve, C. (1966). Lysosomes in Tetrahymena pyriformis I. Some properties and lysosomal localization of acid hydrolases. Journal of Cellular Physiology 68, 165-176.

NORTH, M. J. \& COOMBS, G. H. (1981). Proteinases of Leishmania mexicana amastigotes and promastigotes: analysis by gel electrophoresis. Molecular and Biochemical Parasitology 3, 293-300.

NoRTH, M. J. \& WhYTE, A. (1984). Purification and characterization of two acid proteinases from Dictyostelium discoideum. Journal of General Microbiology 130, 123-134.

NORTH, M. J., COOMBS, G. H. \& BARRY, J. D. (1983). A comparative study of the proteolytic enzymes of Trypanosoma brucei, $T$. equiperdum, $T$. evansi, $T$. vivax, Leishmania tarentolae and Crithidia fasciculata. Molecular and Biochemical Parasitology 9, 161180.

Pennington, R. J. (1961). Biochemistry of dystrophic muscle. Mitochondrial succinate-tetrazolium reductase and adenosine triphosphatase. Biochemical Journal 80, 649-654.

Sedmak, J. J. \& Grossberg, S. E. (1977). A rapid, sensitive and versatile assay for protein using Coomassie brilliant blue G250. Analytical Biochemistry 79, 544-552.

SUPRYNOWiCz, F. A. \& Allewell, N. M. (1979). Regulation of neutral protease activity through the life cycle of Tetrahymena pyriformis. Biochimica et biophysica acta 585, 488-498. 